\title{
Preparation of Polyoxetane-Polystyrene Composite Resins and Their Use as Polymeric Supports of Phase-Transfer Catalysts
}

\author{
Masatoshi Motol, Shinsuke Nagahara, Hiroshi AkiYAma, \\ Masahide HORIUCHI, and Shigeyoshi KANOH \\ Department of Chemistry and Chemical Engineering, \\ Faculty of Technology, Kanazawa University, \\ Kodatsuno, Kanazawa 920, Japan
}

(Received May 17, 1989)

\begin{abstract}
Soft, moderately polar resins were prepared from isomeric mixtures of $m$ - and $p$ [3-(3-methyl- or 3-ethyl-3-oxetanyl)-2-oxapropyl]styrenes via a cationic ring-opening polymerization of their oxetanyl groups with $\mathrm{BF}_{3} \mathrm{THF}$ followed by radical polymerization of styryl groups of the resultant polyoxetanes with AIBN, or via inverted polymerization. 3-(6-Bromo-2-oxahexyl)3-methyloxetane, its 3-ethyl analogue, and a $m$ - and $p$-isomeric mixture of chloromethylstyrene were used as comonomers in the above resin synthesis for obtaining the polymeric supports with the terminal alkyl bromide and the benzyl chloride in the side chain. Divinylbenzene was also used for preparing polymeric supports of the bead type by suspension polymerization. These pendant halides were quaternized with tributylamine or -phosphine to produce polymeric phase-transfer catalysts which could catalyze etherification reactions of alcohols with alkyl bromides in hexane and $50 \%$ aqueous $\mathrm{NaOH}$. The beads with a pendant quaternary ammonium bromide were conveniently and repeatedly used in this reaction giving an ether product in $65-70 \%$ yields.

KEY WORDS Polyoxetane-Polystyrene Composite Resins / Two-Stage Polymerization / Functional Polymers / Phase-Transfer Catalysis /
\end{abstract}

So far, a variety of functionalized polymers has been synthesized by using various polymeric supports. ${ }^{1}$ Among these polymeric supports, divinylbenzene (10)-cross-linked polystyrenes are the most available and used most widely. ${ }^{2-4}$ However, the characters of the polystyrene supports are not always suitable for the chemical modification of their aromatic rings or pendant functional groups because of the hardness, low polarity, and hydrophobicity, especially when polar or ionic reagents and solvents are used.

In our investigation to create softer, more polar polymer matrixes than those of polystyrene resins, we found two types of new crosslinking agents: 1,8-bis(3-methyl-3-oxetanyl)2,7-dioxaoctane (4a) and an isomeric mixture of $m$ - and $p$-[3-(3-methyl-3-oxetanyl)-2-ox- apropyl]styrenes (6a). ${ }^{5,6}$ These agents were successfully used for preparing insoluble crosslinked polymers containing soft, moderately polar polyether networks by copolymerization with several monomers carrying functional groups at the pendant spacer end. Furthermore, the bifunctional monomers $6 \mathbf{a}$ and $\mathbf{6 b}$ with both oxetanyl and styryl groups are considered to be important key compounds for obtaining various functional polymers by cationic ring-opening or radical copolymerizations using cyclic ethers or vinyl compounds, which have pendant functional groups, as a comonomer. Accordingly, we have prepared several cross-linked polymeric supports by two processes of two-stage polymerizations. In one of these processes, the oxetane rings of $\mathbf{6 a}$ and 6b were cationically polymerized with or with- 
M. Motor et al.

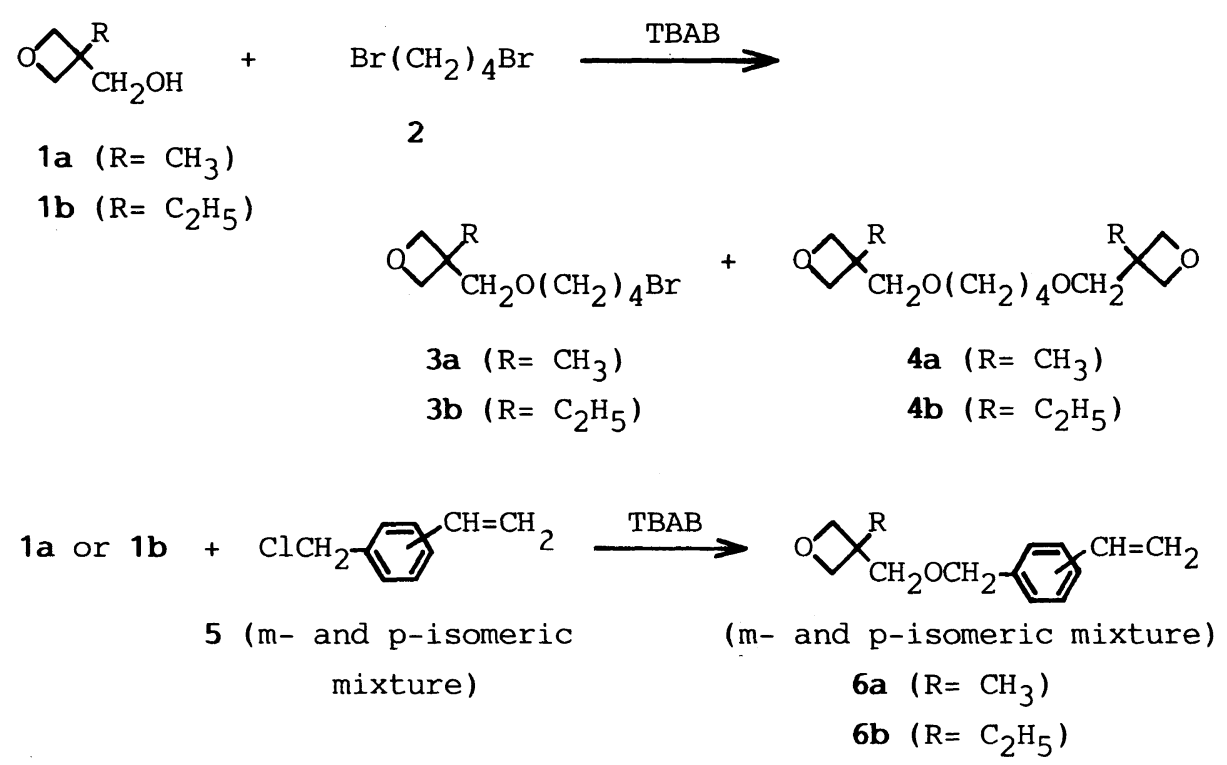

Scheme 1.

out other appropriate cyclic ethers and then the styryl groups of the resultant polyethers were radically polymerized with or without other vinyl monomers. This polymerization process is designated as Method $\mathrm{A}$ in this article. In the other process, designated as Method B, polymerization via the inverted stages of Method A was carried out to prepare the similar polyoxetane-polystyrene composite resins.

Concerning one application of such resins to functional polymeric supports, a phase-transfer catalysis of quaternary ammonium halides attached to the pendant spacer end of polyoxetane-polystyrene resins has been briefly reported by us on etherification reactions between 3-hydroxymethyl-3-methyloxetane (1a) and 1,4-dibromobutane (2). ${ }^{6}$ In this paper, we report the preparation of polyoxetane-polystyrene composite polymers as polymeric supports carrying quaternary onium salts at the pendant spacer ends and, in more detail, their use as polymeric phase-transfer catalysts (PTC) for producing ethers from hydroxy compounds and alkyl halides.

\section{EXPERIMENTAL}

\section{Materials}

3-Methyl- and 3-ethyl-3-hydroxymethyloxetanes (1a and 1b), ${ }^{7,8}$ oxetane (7), ${ }^{9} 3,3$-dimethyloxetane $(\mathbf{8})^{10}$ were prepared according to methods of the literatures. 3a and 4a were prepared by a phase-transfer catalytic reaction between $1 \mathrm{a}$ and $\mathbf{2}$ in the presence of tetrabutylammonium bromide (TBAB), as reported by us previously. ${ }^{5}$ Similarly, 3-ethyl-substituted analogues $\mathbf{3 b}$ and $\mathbf{4 b}$ were obtained.

3-(6-Bromo-2-oxahexyl)-3-ethyloxetane (3b). bp $79^{\circ} \mathrm{C}(18.7 \mathrm{~Pa}$ ); IR (neat) 1120 (acyclic ether), and 980 and $835 \mathrm{~cm}^{-1}$ (cyclic ether); NMR $\left(\mathrm{CDCl}_{3}\right) \delta 0.82\left(3 \mathrm{H}, \mathrm{t}, J=7.3 \mathrm{~Hz}, \mathrm{CH}_{2}-\right.$ $\left.\mathrm{CH}_{3}\right), 1.56-2.08$ [total $6 \mathrm{H}: \mathrm{m}, \mathrm{OCH}_{2}\left(\mathrm{CH}_{2}\right)_{2}-$ $\left.\mathrm{CH}_{2} \mathrm{Br} ; \mathrm{q}(\delta=1.74), J=7.3 \mathrm{~Hz}, \mathrm{C}_{2} \mathrm{CH}_{3}\right]$, $3.32-3.60$ [total $6 \mathrm{H}: \mathrm{t}(\delta=3.45), J=6.0 \mathrm{~Hz}$, $\mathrm{CH}_{2} \mathrm{Br} ; \mathrm{t}(\delta=3.50), J=5.9 \mathrm{~Hz}, \mathrm{OCH}_{2}\left(\mathrm{CH}_{2}\right)_{3}-$ $\mathrm{Br} ; \mathrm{s}(\delta=3.52), \mathrm{CH}_{2}$ adjacent to the oxetane ring], and 4.44 and $4.38 \mathrm{ppm}$ (each $2 \mathrm{H}$, each d, $J=5.9 \mathrm{~Hz}, \mathrm{CH}_{2}$ of the oxetane ring). After being redistilled three times, this product showed the following elemental analysis values: C, $48.20 \%$; H, 7.83\%; Br, 31.02\% (Calcd 
Polyoxetane-Polystyrene Composite Resins

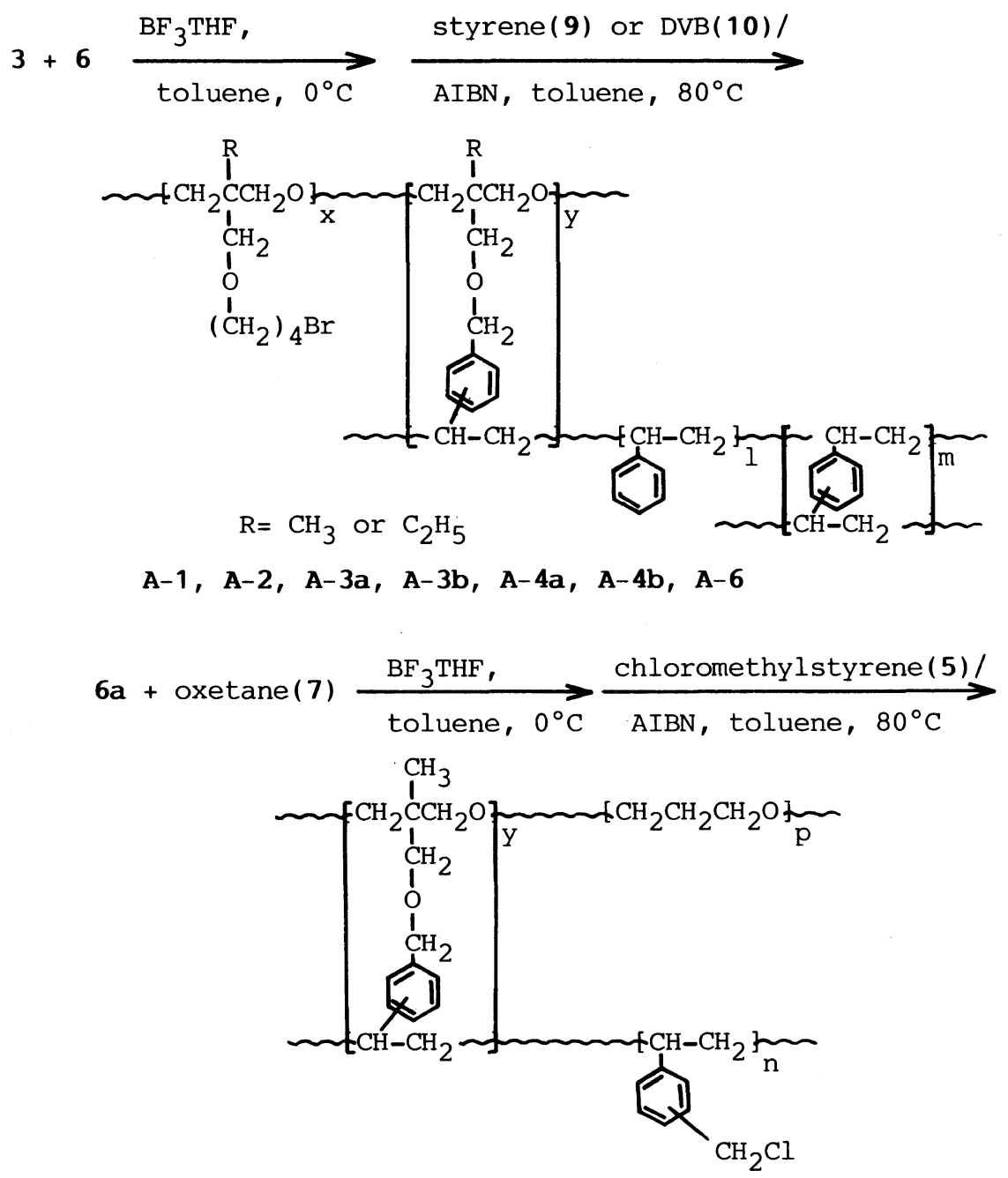

A-5

Scheme 2.

for $\mathrm{C}_{10} \mathrm{H}_{19} \mathrm{BrO}_{2}: \mathrm{C}, 47.81 \% ; \mathrm{H}, 7.64 \% ; \mathrm{Br}$, $31.81 \%$ ).

1,8-Bis(3-elhyl-3-oxetanyl)-2,7-dioxaoctane (4b). bp $123^{\circ} \mathrm{C}(20.0 \mathrm{~Pa})$; IR (neat) 1120 (acyclic ether), and 990 and $840 \mathrm{~cm}^{-1}$ (cyclic ether); $\mathrm{NMR}\left(\mathrm{CDCl}_{3}\right) \delta 0.88(6 \mathrm{H}, \mathrm{t}, J=7.5 \mathrm{~Hz}$, $\mathrm{CH}_{2} \mathrm{CH}_{3}$ ), 1.52-1.90 [total $12 \mathrm{H}: \mathrm{m}, \mathrm{OCH}_{2}-$ $\left(\mathrm{CH}_{2}\right)_{2} \mathrm{CH}_{2} ; \mathrm{q}(\delta=1.74), J=7.3 \mathrm{~Hz}, \mathrm{CH}_{2}-$ $\mathrm{CH}_{3}$ ], 3.36-3.60 [total $8 \mathrm{H}$ : triplet-like $(\delta=$ 3.48), $\mathrm{OCH}_{2}\left(\mathrm{CH}_{2}\right)_{2} \mathrm{CH}_{2} \mathrm{O} ; \mathrm{s}(\delta=3.52), \mathrm{CH}_{2}$ adjacent to the oxetane ring], and 4.45 and
$4.38 \mathrm{ppm}$ (each $2 \mathrm{H}$, each d, $J=5.8 \mathrm{~Hz}, \mathrm{CH}_{2}$ of the oxetane ring).

Anal. Calcd for $\mathrm{C}_{16} \mathrm{H}_{30} \mathrm{O}_{4}: \mathrm{C}, 67.08 \% ; \mathrm{H}$, $10.58 \%$. Found: C, $66.97 \%$; $\mathrm{H}, 10.78 \%$.

An Isomeric Mixture of $m$ - and $p$-[3-(3Methyl-3-oxetanyl)-2-oxapropyl]styrenes (6a) and Its 3-Ethyl Analogue (6b). Into a threenecked flask fitted with a mechanical stirrer, a condenser, and a thermometer, there were placed 1a or $\mathbf{1 b}(97.9 \mathrm{mmol})$, TBAB $(4.89 \mathrm{mmol}), 50 \%$ aqueous sodium hydroxide 


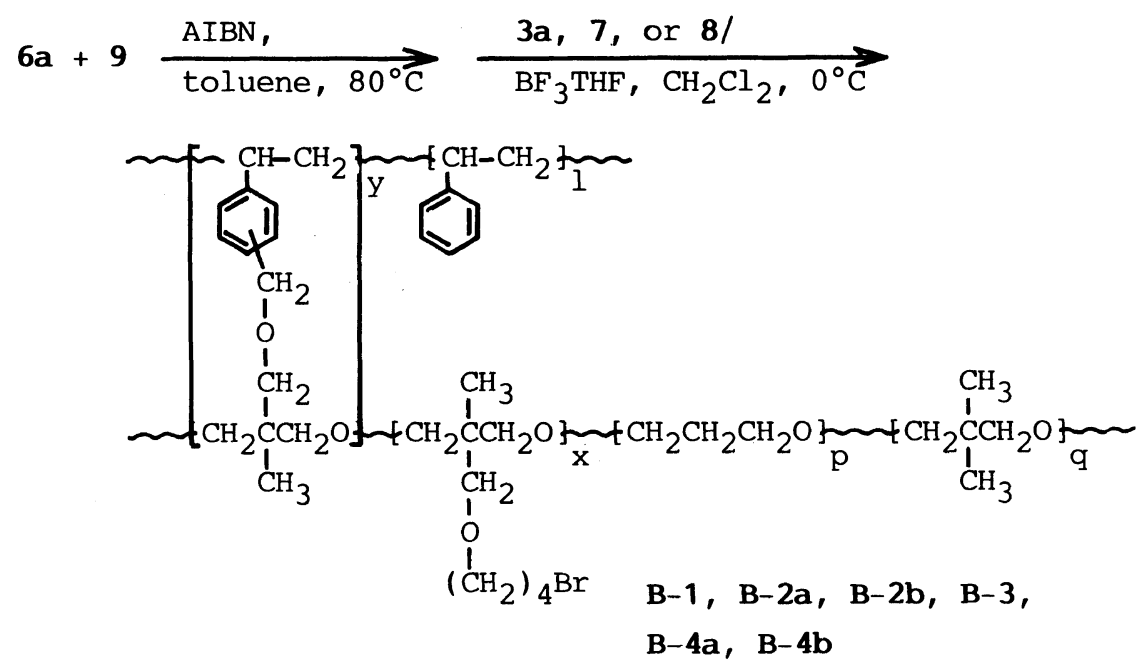

Scheme 3.

$(\mathrm{NaOH})(130 \mathrm{~g})$, and hexane $(70 \mathrm{ml})$. Into this mixture cooled in an ice-bath, was added an isomeric mixture of $m$ - and $p$-chloromethylstyrenes (5), which was used without further purification of a commercially available reagent. The contents of the flask were vigorously stirred at $25-30^{\circ} \mathrm{C}$ for $7 \mathrm{~h}$ and then mixed with water $(100 \mathrm{ml})$ below $5^{\circ} \mathrm{C}$. An organic layer was extracted with ether, washed with a saturated aqueous sodium chloride, and dried over $\mathrm{Na}_{2} \mathrm{SO}_{4}$. The organic layer, after adding hydroquinone $(1.0 \mathrm{~g})$ as an inhibitor to it, was distilled to give a fraction boiling at $117^{\circ} \mathrm{C} / 47 \mathrm{~Pa}$ for $3 \mathrm{a}$ or $110^{\circ} \mathrm{C} / 12 \mathrm{~Pa}$ for $3 \mathbf{b}$. The fraction was washed with $1 \mathrm{moll}^{-1} \mathrm{NaOH}$ $(100 \mathrm{ml})$, and the organic layer was dried over $\mathrm{Na}_{2} \mathrm{SO}_{4}$ and redistilled over copper(I) chloride $(0.4 \mathrm{~g})$ to give pure $3 \mathbf{a}(77 \%)$ or $3 \mathbf{b}(66 \%)$.

3a: bp $102^{\circ} \mathrm{C}(46.7 \mathrm{~Pa})$; IR (neat) 1635 and 910 (vinyl), 1605, 1515, 830, and 715 (aromatic), 1100 (acyclic ether), and 980 and $830 \mathrm{~cm}^{-1}$ (cyclic ether); ${ }^{1} \mathrm{H}$ NMR $\left(\mathrm{CDCl}_{3}\right) \delta$ $1.32\left(3 \mathrm{H}, \mathrm{s}, \mathrm{CH}_{3}\right), 3.49$ and 3.50 (each $2 \mathrm{H}$, each $\mathrm{s}$, isomeric $\mathrm{CH}_{2}$ adjacent to the oxetane ring), 4.35 and 4.51 (each $2 \mathrm{H}$, each d, $J=5.9 \mathrm{~Hz}$, $\mathrm{CH}_{2}$ of the oxetane ring), $4.54\left(2 \mathrm{H}, \mathrm{s}, \mathrm{CH}_{2} \mathrm{Ar}\right)$, $5.14-5.32,5.60-5.86$, and $6.52-6.86$ (each $1 \mathrm{H}$, each dd, $J_{\mathrm{ab}}=1.0, J_{\mathrm{ac}}=10.8$, and $J_{\mathrm{bc}}=$
$17.8 \mathrm{~Hz}$, vinyl protons), and $7.2-7.4 \mathrm{ppm}(4 \mathrm{H}$, $\mathrm{m}, \mathrm{ArH})$.

3b: bp $110^{\circ} \mathrm{C}(13.3 \mathrm{~Pa})$ IR (neat) 1635 and 910 (vinyl), 1605, 1580, 1515, 830, 800, and 715 (aromatic), 1100 (acyclic ether), and 980 and $830 \mathrm{~cm}^{-1}$ (cyclic ether); ${ }^{1} \mathrm{H}$ NMR $\left(\mathrm{CDCl}_{3}\right) \delta$ $0.89\left(3 \mathrm{H}, \mathrm{t}, J=7.2 \mathrm{~Hz}, \mathrm{CH}_{2} \mathrm{CH}_{3}\right), 1.80(2 \mathrm{H}, \mathrm{q}$, $\left.J=7.2 \mathrm{~Hz}, \mathrm{CH}_{2} \mathrm{CH}_{3}\right), 3.6\left(2 \mathrm{H}, \mathrm{s}, \mathrm{CH}_{2}\right.$ adjacent to the oxetane ring), 4.42 and 4.50 (each $2 \mathrm{H}$, each d, each $J=6.0 \mathrm{~Hz}, \mathrm{CH}_{2}$ of the oxetane ring), $4.60\left(2 \mathrm{H}, \mathrm{s}, \mathrm{CH}_{2} \mathrm{Ar}\right), 5.14-5.45,5.58-$ 6.03, and 6.52-7.11 (each $1 \mathrm{H}$, each dd, $J_{\mathrm{ab}}=$ $1.4, J_{\mathrm{ac}}=10.6$, and $J_{\mathrm{bc}}=17.8 \mathrm{~Hz}$, vinyl protons), and 7.2-7.6 ppm (4H, m, ArH).

Dichloromethane (DCM) and toluene as polymerization solvents were twice distilled over calcium hydride under nitrogen. Styrene (9), chloromethylstyrene (5 as a mixture of $m$ and $p$-isomers), and divinylbenzene (10) as comonomers of radical polymerization were purified in the ordinary way. The other reagents and solvents were used without further purification of commercially available reagents (extra pure grade). The authentic samples used for gas chromatography (GLPC) analysis in phase-transfer catalysis were obtained the same way as that described by us previously. ${ }^{11}$ 


\section{Polymerization}

Two-Step Polymerizations: Typical Procedure. In a ground-glass test tube $(200 \phi \times$ $180)$, dried and flushed with dry nitrogen, $4 \mathrm{a}(6.92 \mathrm{mmol}), 7(7.06 \mathrm{mmol})$, and dry toluene $(2.2 \mathrm{ml})$ were placed by a hypodermic syringe under an atmosphere of nitrogen. Into this a $0.5 \mathrm{~mol}^{-1}$ solution of a trifluoroborane $\left(\mathrm{BF}_{3}\right)$-tetrahydrofuran(THF) complex in DCM $(0.14 \mathrm{ml}, 0.5 \mathrm{~mol} \%$ to the oxetanyl group) was added as an initiator at $-50^{\circ} \mathrm{C}$. The test tube was closed with a groundglass stopper and then allowed to stand in an ice-bath for $20 \mathrm{~h}$. Into the resultant solution of polyoxetane C-5 in toluene, 5 (9.96 $\mathrm{mmol}$ ) and azobisisobutyronitrile (AIBN) (33 $\mathrm{mg}, 1.4 \mathrm{~mol} \%$ to the styryl group) were added directly at room temperature. The test tube was stoppered again and heated at $80^{\circ} \mathrm{C}$ for $6 \mathrm{~h}$. A gelatinous, somewhat hardened polymer A-5 was crushed, washed successively with $10 \%$ aqueous methanol, methanol, and ether, and dried in vacuo (yield, $74 \%$ ). Polymerization by Method B was also carried out almost similarly as described above at each stage except using DCM as a solvent at the second stage, i.e., the resultant polystyrene was isolated by reprecipitation using a toluene-methanol system and then dried thoroughly to use it for subsequent cationic ring-opening polymerization.

Suspension Polymerization for Producing Polymer Beads. Polyoxetane C-4 was obtained from 6a $(5.96 \mathrm{mmol})$ and 3a $(10.33 \mathrm{mmol})$ in dry toluene $(10 \mathrm{ml})$ by cationic ring-opening copolymerization. The resultant solution of $\mathbf{C}$ 4 was mixed with $43 \mathrm{mg}$ of AIBN and $0.16 \mathrm{mmol}$ of 10 (charged in $38 \mathrm{mg}$ of a commercially available reagent with $55 \%$ purity for 10), and then added into a mixture of poly(vinyl alcohol) $(0.56 \mathrm{~g})$, calcium carbonate $(0.47 \mathrm{~g})$, and water $(40 \mathrm{ml})$ with vigorous stirring. After stirring at $80^{\circ} \mathrm{C}$ for $6 \mathrm{~h}$, the polymer product A-4a was obtained in a $83 \%$ yield by the ordinary work-up. ${ }^{12}$

\section{Phase-Transfer Catalytic Reaction}

Polymeric PTCs were prepared by heating terminal bromine-containing resins with a threefold molar excess of tributylamine (11) or -phosphine (12) in $N, N$-dimethylformamide (DMF) at $100^{\circ} \mathrm{C}$ for $6 \mathrm{~h}$. The polymeric PTCs were filtered, washed successively with methanol and ether, and dried in vacuo to be subjected to elemental analysis for nitrogen or phosphorous.

In a round-bottomed flask were placed a polymeric PTC, a hydroxy compound, an alkyl halide, and an internal standard of GLPC. A $50 \%$ aqueous $\mathrm{NaOH}$ solution and an organic solvent were added to this mixture of the reactants with ice-cooling. This was heated under reflux with stirring by means of a magnetic stirrer. At specified times, the mixture was cooled below $5^{\circ} \mathrm{C}$ and aliquots of an organic layer were withdrawn into a microsyringe to determine product yields by GLPC.

\section{Measurements}

GLPC analysis of the products was performed by a Shimadzu GC 8A apparatus: glass column $(3.2 \phi \times 1 \mathrm{~m})$ packed with Silicone High Vaccum Grease $(30 \%) /$ Celite $(80-100$ mesh); carrier gas, $\mathrm{He}\left(66 \mathrm{ml} \mathrm{min}^{-1}\right)$; temp, 140 or $210^{\circ} \mathrm{C}$. The IR spectra were recorded on a JASCO A-202 spectrometer, and ${ }^{1} \mathrm{H}$ NMR on a 60 (Hitachi R-24B) or a $100 \mathrm{MHz}$ instrument (JEOL FX-100S) using $\mathrm{CDCl}_{3}$ as a solvent and TMS as an internal standard.

\section{RESULTS AND DISCUSSION}

\section{Preparation of Monomers and Polymers}

Etherification reactions of $\mathbf{1 a}$ with alkyl halides proceeded readily under phase-transfer catalytic conditions to give the desired products in fairly good yields, as reported in our previous paper. ${ }^{5}$ According to this convenient method, we also prepared bifunctional monomers 6a and $\mathbf{6 b}$ with both oxetanyl and styryl groups susceptible to cationic ringopening and radical polymerizations, respec- 
tively. The etherification reaction between 1 and 5 proceeded satisfactorily at about $30^{\circ} \mathrm{C}$ rather than at reflux temperature; reactions at higher temperatures tended to give undesired by-products, resulting in a very low yield of the desired product. The structures of $\mathbf{6 a}$ and $\mathbf{6 b}$ were confirmed on the basis of their IR and ${ }^{1} \mathrm{H}$ NMR spectroscopy. GLPC chromatograms of 6a and $6 \mathbf{b}$ indicated two peaks due to $m$ - and $p$ isomers in a ratio of about $1: 2$, but otherwise did not show peaks of by-products. The ${ }^{1} \mathrm{H}$ NMR spectrum of $\mathbf{6 a}$ also showed two singlets at 3.49 and $3.50 \mathrm{ppm}$ for methylene protons adjacent to the oxetane ring in a $1: 2$ molar mixture of $m$ - and $p$-isomers. Those monomers gave a gel products readily via cationic ringopening polymerization followed by radical polymerization (Method A) or via the inverted two-stage polymerization (Method B). At each stage of these two-stage polymerizations for polymer synthesis, oxetanes $\mathbf{3 a}, \mathbf{3 b}, \mathbf{7}$, and $\mathbf{8}$, or styrenes 5, 9, and 10 could be employed as comonomers, as shown in Schemes 2 and 3. Thus, several polyoxetane-polystyrene composite resins were obtained and summarized in Tables I and II. Polymer beads were prepared according to the ordinary method of suspension polymerization. Elemental analyses for $\mathbf{6 a}$ and 6b were not carried out to confirm their structures, because they tended to polymerize on storage above room temperature. However, elemental analysis values of R-2 and R-6 are close to the calculated values for homopolymers of $\mathbf{6 a}$ and $\mathbf{6 b}$, respectively. Elemental analysis could also be applied for the identification of copolymers of $6 a$ and $6 b$ with 9 (R-4 and $\mathbf{R}-7$, respectively). In ${ }^{1} \mathrm{~N}$ NMR spectra of 6a and $\mathbf{R - 1}$ in $\mathrm{CDCl}_{3}$, and of $\mathbf{C - 2}$ in toluene, $\mathbf{6 a}$ showed an $\mathrm{AB}$ quartet due to methylene protons of an oxetane ring at $4.31-4.54 \mathrm{ppm}$ and an ABC coupling mode due to vinyl protons at 5.1-6.9 ppm, while polymers R-1 and C-1 showed, respectively, no signals assignable to the vinyl and the cyclic methylene protons. Monomer 6a showed IR bands due to the cyclic ether of an oxetane ring at 980 and
Table I. Preparation of polyoxetane-polystyrene resins by Method $A^{a}$

\begin{tabular}{|c|c|c|c|c|}
\hline \multicolumn{2}{|c|}{$\begin{array}{l}\text { Polymer obtained } \\
\text { at 1st stage }\end{array}$} & \multicolumn{3}{|c|}{ Resins obtained at 2 nd stage } \\
\hline \multirow{2}{*}{ Name } & Monomer & \multirow{2}{*}{ Name } & $\begin{array}{c}\text { Monomeric } \\
\text { unit }\end{array}$ & \multirow{2}{*}{$\frac{\text { Yield }^{\circ}}{\%}$} \\
\hline & (Mole ratio) & & (Mole ratio) $^{\mathbf{b}}$ & \\
\hline$C-1^{d}$ & $\mathbf{6 a}$ & A-1 & 6a & 86 \\
\hline C-2 & $6 \mathbf{a}$ & A-2 & $6 a /[9](44 / 56)$ & 88 \\
\hline \multirow[t]{2}{*}{$\mathrm{C}-\mathbf{3}^{\mathrm{e}}$} & $\mathbf{6 a} / \mathbf{3 a}(44 / 56)$ & $\mathbf{A}-\mathbf{3 a}$ & $\mathbf{6 a} / \mathbf{3 a}(44 / 56)$ & 84 \\
\hline & & $\mathbf{A}-\mathbf{3 b}$ & $\begin{array}{l}\mathbf{6 a} / \mathbf{3 a} /[\mathbf{9 ]} \\
\quad(22 / 28 / 50)\end{array}$ & 77 \\
\hline \multirow[t]{2}{*}{$\mathrm{C}-4^{\mathrm{e}}$} & $\mathbf{6 a} / \mathbf{3 a}(37 / 63)$ & $A-4 a^{f}$ & $\begin{array}{c}\mathbf{6 a} / \mathbf{3 a} /[10] \\
(36 / 63 / 1)\end{array}$ & 83 \\
\hline & & $A-4 b^{f}$ & $\begin{array}{c}\mathbf{6 a} / \mathbf{3 a} /[10] \\
(35 / 63 / 2)\end{array}$ & 86 \\
\hline C-5 & $6 a / 7(51 / 49)$ & A-5 & $\begin{array}{l}\mathbf{6 a / 7 / [ 5 ]} \\
\quad(29 / 30 / 41)\end{array}$ & 74 \\
\hline C-6 & $\mathbf{6 b} / \mathbf{3 b}(39 / 61)$ & A-6 & $\mathbf{6 b} / \mathbf{3 b}(39 / 61)$ & 83 \\
\hline $\mathrm{C}-7^{8}$ & $\mathbf{4 a} / \mathbf{3 a}(50 / 50)$ & & & \\
\hline C-8 $8^{\mathrm{g}}$ & $\mathbf{4 a} / \mathbf{3 a}(30 / 70)$ & & & \\
\hline
\end{tabular}

a See the Experimental part for polymerization conditions.

b Monomeric units in brackets indicate comonomers charged at the 2 nd stage. The mole ratio of monomeric units of a resin was estimated from mole amounts for monomers charged at the 1 st and 2 nd stages.

c Based on the weight of a product polymer.

d The polymer yield was $99 \%$ on the basis of the polymer weight obtained from an aliquot of the polymerization solution.

e This polymer was bisected and each part was used at the 2nd stage.

f Obtained by suspension polymerization at the 2nd stage.

g Polyoxetane resins obtained only by cationic ringopening copolymerization.

$830 \mathrm{~cm}^{-1}$ and those due to the vinyl group of styryl residues at 1635 and $910 \mathrm{~cm}^{-1}$. C-1 obtained as an aliquot from the cationic ringopening polymerization solution of $\mathbf{6 a}$ showed IR bands of the vinyl group, but no bands of the oxetane ring. A-1 obtained by radical polymerization of C-1 (Method A) showed only quite weakened intensities of IR bands due to the vinyl group for these polymerizable functional groups, compared with those of $\mathbf{6 a}$ (Figure 1a). Similarly, B-6 obtained by cat- 
Table II. Preparation of polyoxetane-polystyrene resins by Method $\mathbf{B}^{\mathrm{a}}$

\begin{tabular}{|c|c|c|c|c|c|}
\hline \multicolumn{3}{|c|}{ Polymer obtained at 1st stage } & \multicolumn{3}{|c|}{ Resin obtained in 2 nd stage } \\
\hline \multirow{2}{*}{ Name } & Monomer & Yield $^{b}$ & \multirow{2}{*}{ Name } & Monomeric unit & Yield $^{\mathrm{d}}$ \\
\hline & (Mole ratio) & $\%$ & & $(\text { Mole ratio })^{\mathrm{c}}$ & $\%$ \\
\hline R-1 & $\mathbf{6 a}$ & 85 & B-1 & $6 \mathbf{6 a} /[3 \mathbf{a}](20 / 80)$ & 91 \\
\hline \multirow[t]{2}{*}{$\mathbf{R}-\mathbf{2}^{\mathrm{e}, \mathrm{f}}$} & $\mathbf{6 a}$ & ca. 100 & B-2a & $\mathbf{6 a} /[\mathbf{3 a}](51 / 49)$ & 85 \\
\hline & & & $\mathbf{B}-\mathbf{2 b}$ & $\mathbf{6 a} /[\mathbf{3 a}] /[7](15 / 14 / 71)$ & 76 \\
\hline $\mathbf{R}-\mathbf{3}$ & $\mathbf{6 a}$ & ca. 100 & B-3 & $\mathbf{6 a} /[\mathbf{8}](17 / 83)$ & 89 \\
\hline \multirow[t]{2}{*}{$\mathbf{R}-4^{\mathrm{e}, \mathrm{g}}$} & $\mathbf{6 a} / 9(50 / 50)$ & 79 & B-4a & $6 \mathbf{a} /[3 \mathbf{a}] / 9(32 / 32 / 36)$ & 91 \\
\hline & & & B-4b & $6 \mathbf{6} /[3 \mathbf{3}] / 9(12 / 12 / 76)$ & 92 \\
\hline $\mathbf{R}-5^{\text {h }}$ & $6 a / 9(33 / 67)$ & 81 & & & \\
\hline $\mathbf{R}-\mathbf{6}^{\mathbf{i}}$ & 6b & 90 & B-6 & $\mathbf{6 b}$ & 95 \\
\hline $\mathbf{R}-\mathbf{7}^{\mathrm{h}, \mathrm{j}}$ & $6 b / 9(42 / 58)$ & ca. 100 & & & \\
\hline
\end{tabular}

a See the Experimental part for polymerization conditions.

b Based on the weight of a product polymer obtained by reprecipitation using a chloroform-methanol system.

c Monomeric units in brackets indicate comonomers charged at the 2nd stage. The mole ratio of monomeric units of a resin was estimated from mole amounts for monomers charged both at the 1 st and 2 nd stages.

d Based on the weight of a resin.

e This polymer was bisected and each part was used at the 2nd stage.

f Anal. Calcd for $\left(\mathrm{C}_{14} \mathrm{H}_{18} \mathrm{O}_{2}\right)_{n}$ : C, $77.02 \% ; \mathrm{H}, 8.33 \%$. Found: C, 76.5\%, 76.55\%; H, 8.32\%, 8.29\%.

g Anal. Calcd for $\left[\left(\mathrm{C}_{14} \mathrm{H}_{18} \mathrm{O}_{2}\right)_{0.5}\left(\mathrm{C}_{8} \mathrm{H}_{8}\right)_{0.5}\right]_{n}$ : C, 81.95\%; H, 8.14\%. Found: C, 81.3\%, 81.01\%; H, 8.10\%, 8.14\%

h Only radical polymerization was performed.

i Anal. Calcd for $\left(\mathrm{C}_{15} \mathrm{H}_{20} \mathrm{O}_{2}\right)_{n}$ : C, 77.53\%; H, 8.69\%. Found: C, 77.42\%,77.49\%; H, 8.78\%, 8.63\%.

j Anal. Calcd for $\left[\left(\mathrm{C}_{15} \mathrm{H}_{20} \mathrm{O}_{2}\right)_{0.42}\left(\mathrm{C}_{8} \mathrm{H}_{8}\right)_{0.58}\right]_{n}: \mathrm{C}, 83.14 \% ; \mathrm{H}, 8.69 \%$. Found: C, $82.44 \%, 82.59 \% ; \mathrm{H}, 8.39 \%, 8.34 \%$.

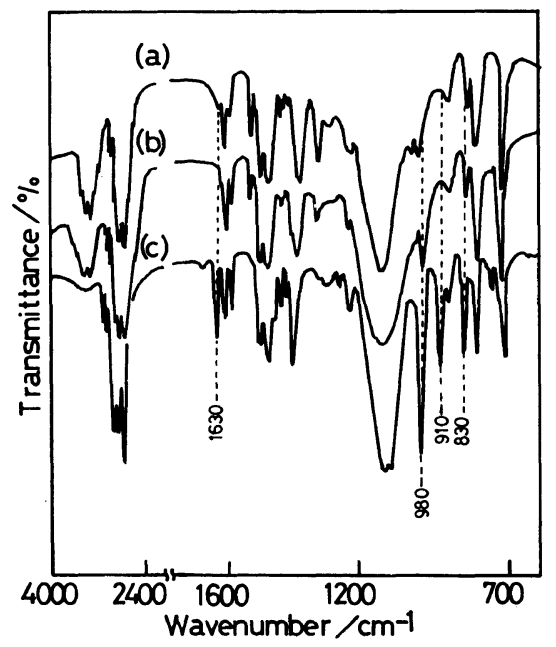

Figure 1. IR spectra of polyoxetane-polystyrene resins (a) A-1 and (b) B-6 (KBr disk), and of (c) monomer 6a (neat). ionic ring-opening polymerization of R-6 (Method B) showed no IR bands due to the vinyl group and IR bands with very weak intensities due to the oxetanyl group (Figure 1b).

C-1 was soluble in usual solvents such as DCM, toluene, chloroform, and acetone, and became insoluble in these solvents by standing the polymer in the light over a certain period. The other polymers obtained in this study were also at least soluble in DCM and toluene. In the second-stage polymerization, cross-linkages of 1,3- and 1,4-phenylene-2oxatrimethylene chains, $-\mathrm{C}_{6} \mathrm{H}_{4}-\mathrm{CH}_{2} \mathrm{OCH}_{2}-$, must be formed between polyoxetane and polystyrene backbones. In copolymerizations with oxetanyl or vinyl comonomers, their oligo- or polymeric chains may be formed as caross-linking, grafting, or looping segments. It seemed to be difficult at this time to clarify these complicated structures satisfactorily. 


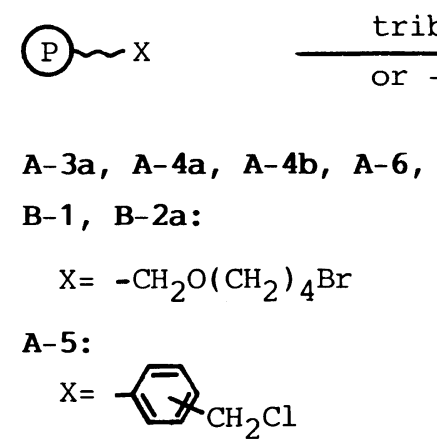

A-3aN, A-4aN, A-4bN, A-6N,

$B-1 N, B-2 a N:$

$\mathrm{Y}=-\mathrm{CH}_{2} \mathrm{O}\left(\mathrm{CH}_{2}\right){ }_{4} \mathrm{~N}^{+}\left(\mathrm{n}-\mathrm{C}_{4} \mathrm{H}_{9}\right)_{3} \mathrm{Br}^{-}$

B-1P:

$\mathrm{Y}=-\mathrm{CH}_{2} \mathrm{O}\left(\mathrm{CH}_{2}\right)_{4} \mathrm{P}^{+}\left(\mathrm{n}-\mathrm{C}_{4} \mathrm{H}_{9}\right)_{3} \mathrm{Br}^{-}$

A-5N:

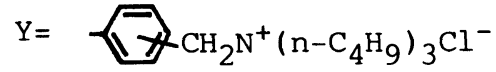

Scheme 4.

Phase-Transfer Catalysis by PolyoxetanePolystyrene Resins with Pendant Quaternary Onium Salts

Preparation of Polymeric PTCs. The terminal alkyl bromide and the benzylic chloride of resins are expected to act as functional groups in various chemical reactions for preparing pendant functions immobilized on a soft, moderately polar polyether network. In this paper, one of the applications in utilizing these resins as a polymeric support is described. Thus, the pendant bromide and chloride of resins were converted to phase-transfer catalytic groups by quaternizing these pendant halides with tributylamine (11) or -phosphine (12) in DMF at $100^{\circ} \mathrm{C}$ as illustrated in Scheme 4, where the complicated structures of the supporting resins are expressed as the following (P) m.

These polymeric PTCs are listed in Table III along with polyoxethane-supported PTCs C7N and $\mathbf{C - 8 N}$. The content of the onium salt in a polymer was estimated on the basis of elemental analysis data for halogen or phosphorus. A mole fraction of the monomeric unit with the catalytic group in a polymeric PTC was not estimated for the present, since information on contaminants, such as moisture, in the PTC was not sufficiently available.

Phase-Transfer Catalysis Using a PTC Supported by the Polyoxetane-Polystyrene
Table III. Polyoxetane-polystyrene resins having pendant quaternary onium salts

\begin{tabular}{|c|c|c|c|}
\hline \multirow{2}{*}{$\begin{array}{l}\text { PTC } \\
\text { name }\end{array}$} & \multirow{2}{*}{$\begin{array}{l}\text { Starting } \\
\text { resin }^{\mathrm{a}}\end{array}$} & \multirow{2}{*}{$\begin{array}{c}\text { Anal }(\%) \text { for } \\
N \text { or } P\end{array}$} & $\begin{array}{l}\text { Content of } \\
\text { onium }^{\text {b }}\end{array}$ \\
\hline & & & meq $\mathrm{g}^{-1}$ \\
\hline$B-1 N^{c}$ & B-1 & N, 2.36 & 1.68 \\
\hline $\mathbf{B}-1 \mathbf{P}^{\mathbf{c}}$ & B-1 & $P, 5.61$ & 1.81 \\
\hline B-2a $\mathbf{N}^{\mathrm{c}}$ & B-2a & $\mathrm{N}, 1.43$ & 1.02 \\
\hline $\mathbf{A}-\mathbf{3 a} \mathbf{N}^{\mathrm{c}}$ & A-3a & $\mathrm{N}, 1.48$ & 1.06 \\
\hline$A-4 a N-I-V^{d}$ & A-4a & $\mathrm{N}, 1.67-1.70^{\mathrm{e}}$ & $1.2^{\mathrm{f}}$ \\
\hline$A-4 b N-I-V^{d}$ & A-4b & $\mathrm{N}, 1.33-1.48^{\mathrm{e}}$ & $1.0^{\mathrm{f}}$ \\
\hline $\mathbf{A}-\mathbf{5} \mathbf{N}^{\mathrm{c}}$ & A-5 & $\mathrm{N}, 1.56$ & 1.11 \\
\hline$A-6 N^{c}$ & A-6 & $\mathrm{N}, 1.10$ & 0.79 \\
\hline$C-7 N^{8}$ & C-7 & $\mathrm{N}, 1.08$ & 0.76 \\
\hline$C-8 N^{g}$ & C-8 & $\mathrm{N}, 1.50$ & 1.07 \\
\hline
\end{tabular}

a These polymers listed in Tables I and II were used as polymeric supports for the preparation of polymeric PTCs.

b Millimoles of a quaternary salt per $\mathrm{g}$ of dry resin.

c Obtained in the shape of sawdust-like masses with a size range of 60 to 100 mesh.

d Sieved and separated into five groups depending on the grain size range of beads: (I) $8-16$, (II) 16-32, (III) $32-60$, (IV) 60-100, and (V) 100-140 mesh.

e Nitrogen content for each group of (I)-(V) was determined between these values.

f An average value.

g Obtained as somewhat adhesive, elastic masses with a size of 8 mesh at the most.

Resin. Table IV and Figure 2 show the results of a phase-transfer catalytic reaction of $\mathbf{1 a}$ with 2 at a molar ratio of $1: 3$ using a poly- 
Polyoxetane-Polystyrene Composite Resins

Table IV. Etherification of 1 a with 2 by phase-transfer catalysis using a polymeric PTC ${ }^{\text {a }}$

\begin{tabular}{|c|c|c|c|c|c|c|c|c|c|}
\hline \multirow{3}{*}{$\begin{array}{l}\text { Run } \\
\text { no. }\end{array}$} & \multirow{2}{*}{\multicolumn{2}{|c|}{ Polymer PTC }} & \multicolumn{7}{|c|}{ Yields of $\mathbf{3 a}$ and $\mathbf{4 a} / \%$} \\
\hline & & & & \multicolumn{6}{|c|}{ Reaction time $/ \mathrm{h}$} \\
\hline & $\left(\mathrm{mol}^{\%} / \mathrm{tc}\right.$ & $0(\mathbf{a})^{b}$ & & 0.5 & 1.0 & 1.5 & 2.0 & 2.5 & 3.0 \\
\hline \multirow{2}{*}{1} & $\mathbf{A}-\mathbf{3 a N}$ & $(2.7)$ & 3a: & 15.3 & 34.0 & 45.7 & 53.8 & 55.7 & 57.3 \\
\hline & & & 4a: & 0.4 & 2.6 & 3.6 & 5.9 & 6.0 & 7.0 \\
\hline \multirow[t]{2}{*}{2} & B-2aN & $(2.3)$ & 3a: & 54.6 & 66.5 & 65.2 & 66.5 & & \\
\hline & & & 4a: & 3.2 & 4.4 & 4.9 & 5.8 & & \\
\hline \multirow[t]{2}{*}{3} & B-1N & $(2.5)$ & 3a: & 16.9 & 31.6 & 45.7 & 69.4 & 79.4 & 79.4 \\
\hline & & & 4a: & 1.0 & 3.1 & 4.3 & 5.0 & 5.8 & 5.6 \\
\hline \multirow[t]{2}{*}{4} & $A-6 N$ & $(2.0)$ & 3a: & 18.6 & 43.2 & 48.4 & 50.5 & 60.4 & 64.0 \\
\hline & & & 4a: & 2.0 & 4.3 & 5.2 & 5.6 & 6.5 & 6.9 \\
\hline \multirow[t]{2}{*}{5} & C-7N & (1.1) & 3a: & 50.5 & 68.7 & 77.0 & 80.9 & 84.1 & 85.6 \\
\hline & & & 4a: & 2.0 & 4.3 & 5.2 & 5.6 & 6.5 & 6.9 \\
\hline \multirow[t]{2}{*}{6} & TВAB & $(5.0)$ & 3a: & 83.0 & 81.1 & & & & \\
\hline & & & 4a: & 14.6 & 14.6 & & & & \\
\hline $7^{\mathrm{c}}$ & None & - & 4a: & 2.6 & 3.4 & 4.9 & & & \\
\hline
\end{tabular}

a $1 \mathrm{a}, 1.97 \mathrm{mmol} ; 2,5.87 \mathrm{mmol} ; n-\mathrm{C}_{16} \mathrm{H}_{34}$ (as an internal standard of GLPC), $0.14 \mathrm{mmol} ; 50 \% \mathrm{NaOH}, 2.6 \mathrm{~g}$; hexane, $2.0 \mathrm{ml}$; under reflux.

b As a phase-transfer catalyst (PTC), a dried polymeric PTC or tetrabutylammonium bromide (TBAB) was used.

c No 4a was detected within $1.5 \mathrm{~h}$.

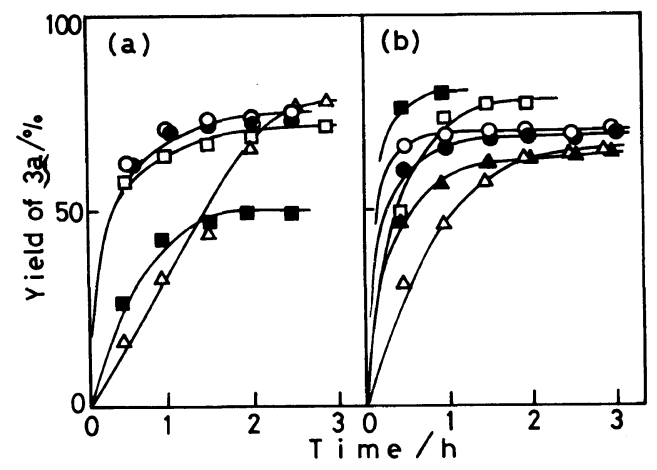

Figure 2. Time-yield curves for $\mathbf{3 a}$ in the reactions between 1a and 2 at a molar ratio of $1: 3$ in hexane- $50 \%$ $\mathrm{NaOH}$ at reflux temperature in the presence of polymeric PTCs. (a): $\mathbf{M o l} \%$ of the ammonium salt of $\mathbf{B}-\mathbf{1 N}$ to $1 \mathrm{a}$ : ( $\triangle$ ) $2.5 ;(\bigcirc) 4.0 ;(\bigcirc) 8.6 ;(\square) 3.8$, without the hexane solvent; ( $\square$ ) 4.0, in benzene. (b): PTC and $\mathrm{mol} \%$ of the onium salt to 1a: $(\bigcirc)$ B-1P, $4.0 ;(\bigcirc), B-1 P, 7.9 ;(\triangle)$ A-

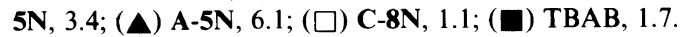

meric catalyst in $50 \%$ aqueous $\mathrm{NaOH}$ and an appropriate organic solvent. In our previous paper, it was proved that $\mathbf{3} \mathbf{a}$ was produced in fairly good yields by phase-transfer catalysis at a 1a/2 molar ratio of $1: 3$ in the presence of
TBAB or polyoxetane-supported PTCs C-7N and C-8. ${ }^{5,11}$ The present polymeric PTCs could also catalyze this reaction to produce $\mathbf{3 a}$ in $60-80 \%$ yields, which were comparable to or lower than that with TBAB (Run no. 6), while a very low yield of 3a was obtained without any catalyst (Run no. 7). With the polymeric PTCs, a product ratio of 3a to $\mathbf{4 a}$ was slightly higher than that with TBAB, probably owing to the $S_{N} 2$ reaction of 1 a with 3a, a bulkier bromide than $\mathbf{2}$, in sterically crowded polymer matrixes. However, the polymeric PTC A-6N with an ethyl substituent gave a yield of $\mathbf{3 a}$ comparable to that in the presence of $\mathbf{A - 3 a N}$ with a less bulky methyl substituent (Run no. 1 and 4).

Although B-2aN was taken to be near A3aN with respect to monomeric unit compositions of their supports, B-2aN gave 3a in a higher yield and at a higher rate than $\mathbf{A}-3 \mathbf{a N}$ used in a comparable amount of the catalytic group (respectively, 2.7 and $2.3 \mathrm{~mol} \%$ to $1 \mathrm{a}$ ), suggesting that different structures of the resins may be formed by Methods A and B (Run 
no. 1 and 2). On the other hand, a final yield of 3a with B-1N was higher than that with B-2aN, although the catalyst $\mathbf{B}-\mathbf{1 N}$ formed $\mathbf{3 a}$ at a lower rate than B-2aN (Run no. 2 and 3). The higher content of aromatic moieties in B-2aN than in B-1N seems related to the lower yield of 3a (vide infra). Furthermore, polyoxetane networks in less polar solvents such as hexane may require a somewhat prolonged swelling time, probably due to coagurated structures of somewhat adhesive, elastic polyoxetanes; it was found that polyoxetane resin-supported PTCs trended to produce 3a slowly, when used in small amounts of the catalytic group, as exemplified in the use of $\mathbf{C - 8 N}$ in $1.1 \mathrm{~mol} \%$ to $1 \mathrm{a}$.

Hexane, however, was a solvent suitable for the present phase-transfer catalysis, and use of excess $\mathbf{2}$ in place of hexane also gave $\mathbf{3 a}$ in a satisfactory yield, while benzene was not an appropriate solvent (Figure 2a). The catalytic activity of a phosphonium bromide of B-1P was also comparable to those of the corresponding ammonium bromides (Figure $2 b$ ). Formation rates of $\mathbf{3 a}$ hardly increased by increasing amounts of the onium groups from 4.0 to 7.9 or $8.6 \mathrm{~mol}^{\circ} \%$ to $1 \mathrm{a}$. This fact is interpreted as follows. Assembly (or a locally enhanced concentration) of the catalytic groups, due to a high loading or large amount of the used PTC, is not effective for catalysis because of electrostatic and/or steric repulsions between nucleophiles adsorbed on the onium cation as its counteranion. Thus, an adequate amount of the catalytic groups of these immobilized PTCs lies around $2-4 \%$ molar respect to 1a (also see Table IV). The phase-transfer catalysis using those polymeric PTCs based on soft, moderately polar polyoxetane resins is described in another report. ${ }^{11}$

Phase-Transfer Catalysis Using a PTC Supported by Beads of a PolyoxetanePolystyrene Resin Cross-Linked with Divinylbenzene. The resins containing polyoxetane segments appeared to be slightly adhesive to walls of glass and paper. So, when

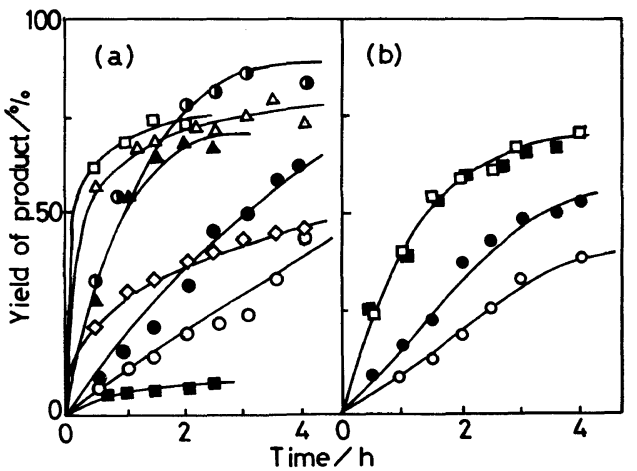

Figure 3. Time-yield curves for $\mathbf{3 a}$ in the reaction at a 1a/2 molar ratio of $1: 3$ using (a) $1 \%$ - and (b) $2 \%$ DVB(10)-cross-linked PTCs in hexane- $50 \% \mathrm{NaOH}$ at reflux temperature. PTC and $\mathrm{mol} \%$ of the ammonium salt to 12. (a): (O) A-4aN-I, 3.9; (O) A-4aN-II, 3.2; $\triangle$ )

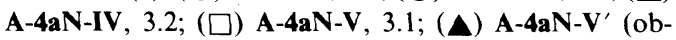
tained by grinding $\mathbf{A}-\mathbf{4 a N}-\mathbf{I}$ into pieces with a grain size range of $100-140$ mesh), 3.3; ( $\diamond) \mathbf{A}-4 \mathbf{a N}-\mathbf{V}, 3.2$, in benzene; (ם) without PTC; ( $\mathbf{(}) \mathbf{A}-\mathbf{4 a N}-\mathbf{V}, 3.0$, butyl bromide (14) was used in place of 2. (b): (O) A-4bN-II, 2.8; (○) A-4bN-III, 2.7; ( $\square$ ) A-4bN-IV, 3.0; (ם) A-4bN$\mathbf{V}, 2.7$.

employed in the phase-transfer catalysis, the resins had a tendency to be lost in about $3 \%$ by weight of the initially used resin upon its recovery via a somewhat modified work-up. ${ }^{11}$ In order to work up the reaction mixture more readily, use of resin supports in the form of beads was examined. The beads of A-4aN and $\mathbf{A}-\mathbf{4 b N}$, which were prepared by an ordinary suspension polymerization from $\mathbf{C}-\mathbf{4}$ and divinylbenzene (10) with AIBN as an initiator, were heated with 11 to quaternize their pendant bromides. The modified beads were sieved to be separated into five groups $\mathbf{I}-\mathbf{V}$ depending on grain sizes of (I) $8-16$, (II) $16-$ 32, (III) $32-60$, (IV) $60-100$, and (V) $100-$ $140 \mathrm{mesh}$. Figure 3 indicates the influence of the grain size and content of $\mathbf{1 0}$ on the yield of 3a. The yield of 3a was improved by decreasing the grain size of a PTC; the yields of $\mathbf{3 a}$ reached maximums of about 76 and $72 \%$, respectively, after $3-4 \mathrm{~h}$ in the presence of $\mathrm{A}$ 4aN and A-4bN with grain sizes below 60 mesh. In addition, the catalytic activity was improved by using A-4aN-V', which was ob- 


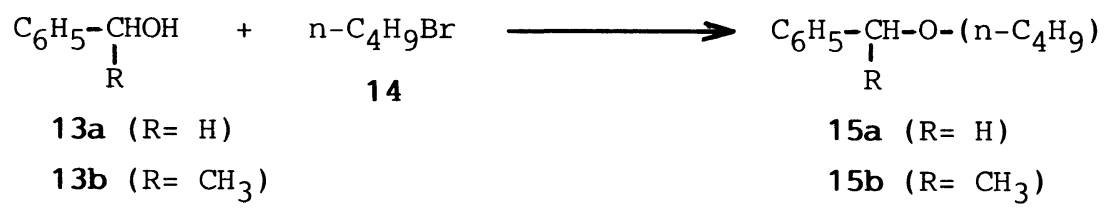

Scheme 5.

tained by grinding A-4aN-I into particles with a grain size range of 100-140 mesh. This indicates that, in PTCs with larger grain sizes, a considerable part of their catalytic groups was confined inside beads of the PTC, and could not realize their phase-transfer catalyzing abilities satisfactorily, although the pendant bromide located inside the beads could react readily with the amine $\mathbf{1 1}$ on quaternization in DMF capable of swelling polymer matrixes of the beads adequately. Lowering the content of $\mathbf{1 0}$ was also favorable for producing 3a more rapidly, indicating that softness was required as a character of the desired polymeric support of PTC.

Figure 4 shows the results of reactions of aralkyl alcohols 13a and 13b with a threefold molar amount of butyl bromide (14) in the presence of A-4aN-I or A-4aN-V. The same tendency of influence of grain size on the yields of 15a and 15b is also observed in Figure 4. Furthermore, steric crowding around the benzylic carbon of a substrate $\mathbf{1 3}$ is thought to lead to a lower rate of the phase-transfer catalysis. With A-4aN-V, 13a was converted into 15a almost quantitatively within $1.5 \mathrm{~h}$, while the etherification of $13 \mathrm{~b}$ with 14 required a reaction period of $3 \mathrm{~h}$ to give a $95 \%$ yield of 15b. Hydrophilicity or hydrophobicity of the PTC support also appears to affect the reaction rate. The yield of the product, 3-(2oxahexyl)-3-methyloxetane, in a reaction between $1 \mathrm{a}$ and 14 with A-4aN-V was about $85 \%$ at the most, compared with the quantitative conversion of 13a into 15a (Figures 3 and 4); benzyl alcohol (13a) is considerably hydrophobic, but 1a is soluble in water. Aromatic rings as hydrophobic components of the polymeric PTC would have affinity for the aro-

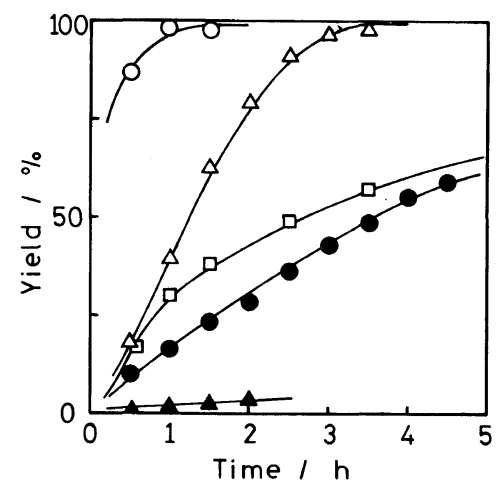

Figure 4. Time-yield curves for 15a $(\bigcirc, \bigcirc, \square)$ and $15 b(\Delta, \triangle)$ in phase-transfer catalytic reactions of 13a or 13b with 14 in hexane $-50 \% \mathrm{NaOH}$ at a $13 / 14$ molar ratio of $1: 3$ under reflux. PTC and $\mathrm{mol} \%$ of the ammonium salt to 13: (O) A-4aN-I, 3.2; ( $)$ A-4aN-V, 3.2; ( $\square$ ) A-4aN-V, 3.1, in benzene; $(\mathbf{A}) \mathbf{A}-4 \mathbf{a N}-\mathbf{I}, 3.1$; ( $\triangle$ ) A-4aN-V, 3.1.

matic reactants, being effective for facilitating their phase-transfer catalysis, especially in nonaromatic solvents such as hexane. On the other hand, since the aromatic components of a polymeric support have also affinity for aromatic solvents such as benzene, not only the hydrophilic 1a but also the more hydrophobic 13a are restricted to penetrate in the form of their alkoxide anions under such extremely hydrophobic circumstances of the resin swollen with the aromatic solvent. B-1N and $\mathbf{A}-\mathbf{4 a N}-\mathbf{V}$ actually indicated lower catalytic activities for phase-transfer catalyses in benzene than in hexane ( $\square$ in Figure $2 a$ and $\square$ in Figure 4).

Figure 5 shows time-yield curves for the formation of $\mathbf{3 a}$ and $\mathbf{4 a}$ by phase-transfer catalysis at a $1 \mathrm{a} / \mathbf{2}$ molar ratio of 1.0 in the presence of each of A-4aN-V, A-6N, C-8N, and TBAB. Under the present reaction condi- 


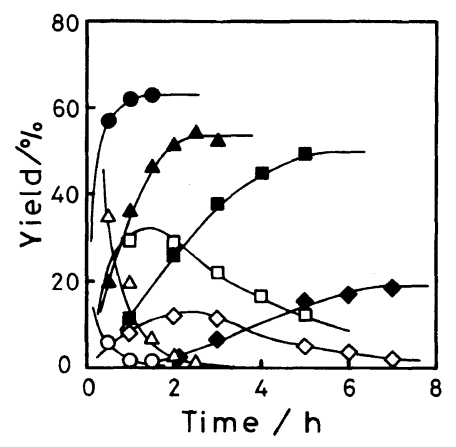

Figure 5. Time-yield curves for $\mathbf{3 a}(\bigcirc, \triangle, \square, \diamond)$ and $\mathbf{4 a}(\bullet, \Delta, \square, \diamond)$ in the phase-transfer catalysis of $\mathbf{1 a}$ with 2 at a molar ratio of $1: 1$ in hexane $-50 \% \mathrm{NaOH}$ at reflux temperature in the presence of a polymeric PTC (3 $\mathrm{mol} \%$ to $1 \mathrm{a})$ or $\mathrm{TBAB}(5 \mathrm{~mol} \%):(\triangle, \triangle) \mathbf{C}-\mathbf{8 N} ;(\square, \square)$ A-4aN-V; $(\diamond, \diamond) \mathbf{A - 6 N} ;(\bigcirc, \diamond)$ TBAB.

tions using TBAB as a PTC, the disubstituted product 4a was formed in a fairly good yield of $65 \%$, while the formation of the monosubstituted product 3a as an intermediate was repressed below a very low yield. The use of $\mathbf{A - 4 a N - V}$ and $\mathbf{C - 8 N}$ as a PTC was not unsatisfactory for producing $\mathbf{4 a}$, as shown by the formation of $\mathbf{4 a}$ at moderate rates. It is, however, noted that bulkiness of polymeric supports affected the rates of conversion of 3a into 4a. Especially, the yield of 4a was remarkably low, when A-6N was used which linked a bulkier ethyl group than the corresponding methyl analogue to the polymer backbone.

Repeated Use of Polymeric PTC in the Etherification Reaction. The repeated use of polymeric PTC was examined in the phasetransfer catalysis using $\mathbf{A}-\mathbf{4 b N}-\mathbf{I V}$ at a molar ratio of 1a to 2 of $1: 3$ in hexane (Figure 6). The final yield of $3 \mathbf{a}$, which was observed at each of the eight stages in a process using PTC repeatedly in the above reaction, was maintained around $60-70 \%$, but the formation rate of $\mathbf{3 a}$ at each stage was different. This seems due to requiring a certain period to swell a resin with the used mediums when using the resin dried thoroughly; such influence of drying of a polymeric PTC on the catalysis was

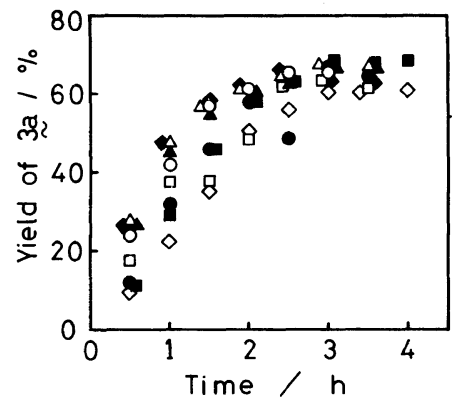

Figure 6. Examination of the repeated use of $\mathbf{A}-\mathbf{4 b N}$ IV for the formation of $\mathbf{3 a}$ by a phase-transfer catalysis at a 1a/2 molar ratio of $1: 3$ in hexane $-50 \% \mathrm{NaOH}$ under reflux: $(\bigcirc)$ the $1 \mathrm{st},(\bigcirc) 2 \mathrm{nd},(\triangle) 3 \mathrm{rd},(\Delta) 4 \mathrm{th},(\square) 5 \mathrm{th}$, $(\square) 6$ th, $(\diamond) 7$ th, and $(\diamond) 8$ th stages in a process using the PTC repeatedly.

also observed in the repeated use of a polyoxetane resin-supported PTC. ${ }^{11}$ This catalyst was hardly adhesive and thereby readily recovered from the reaction mixture by filtration without any loss of the catalyst. Dry weights of the initially and finally used PTCs were 0.55 and $0.57 \mathrm{~g}$, respectively. Thus, the facile workup of a reaction mixture was achieved by using the beads of polyoxetane-polystyrene resins as a polymeric PTC support.

Comparison of Polyoxetane-Polystyrene Resins with Polyoxetane Resins. Polyoxetanepolystyrene resin supports are thought to be somewhat inferior to polyoxetane resin supports, such as $\mathbf{C - 7 N}$ and $\mathbf{C - 8 N}$, in comparison of yields of 3a with each PTC based on these two types of polymeric supports. These polyoxetane resins with quaternary onium bromides were observed to be considerably swellable under applied phase-transfer catalytic conditions, owing to moderate polarity and softness (or elasticity) of the ether function. On the other hand, it is generally known that the existence of less polar, hard polystyrene resins, employed widely and conveniently as a commercially available polymeric support, is not necessarily advantageous for organic synthesis using polar reagents and solvents. It was mentioned above that higher mole fractions of aromatic components and of cross-linking 


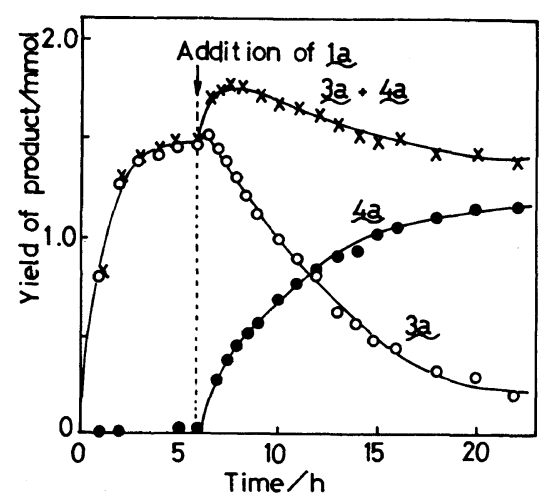

Figure 7. Curves of the amounts of $3 \mathbf{a}$ and $\mathbf{4 a}$, and of their total amount against reaction time for the phasetransfer catalytic reaction of 1a with 2 in hexane- $50 \%$ $\mathrm{NaOH}$ under reflux: 1a, $1.92 \mathrm{mmol} ; 2,5.75 \mathrm{mmol}$; $n$ $\mathrm{C}_{16} \mathrm{H}_{34}$ (internal standard of GLPC determination), $1.07 \mathrm{mmol}$; after a $6 \mathrm{~h}$-reaction, additional $1.94 \mathrm{mmol}$ of 1a were added to the resulting reaction mixture.

agent $\mathbf{1 0}$ in polyoxetane-polystylene resins did not favor the phase-transfer catalysis, being responsible for characteristics of polystyrenes. Grain sizes of the polyoxetane-polystyrene beads appreciably influenced the catalytic activities of polymeric PTCs. The catalytic groups inside the beads virtually could not act as an active group. However, mass sizes of polyoxetane-supported PTCs seem to be unimportant in the present catalysis, since these polyether networks expanded satisfactorily to form oil-like or gelatinous masses under applied reaction conditions. Mass size of polyoxetane-polystyrene resin-supported PTCs was roughly adjusted in a range from 60 to 100 mesh, since they were sawdust-like masses which were sieved somewhat troublesomely. The influence of mass size on catalysis, especially when using PTCs with higher contents of $\mathbf{6 a}$ or $\mathbf{6 b}$, has yet not been clarified.

Beads-like PTCs, however, were also somewhat inferior to PTCs based on polyoxetane resins, as shown in a comparison of product yields on their phase-transfer catalyses. In general, the polyoxetane-polystyrene resinbased PTCs gave products $\mathbf{3 a}$ and $\mathbf{4 a}$ in total yields lower by $3-35 \%$ than the polyoxetane

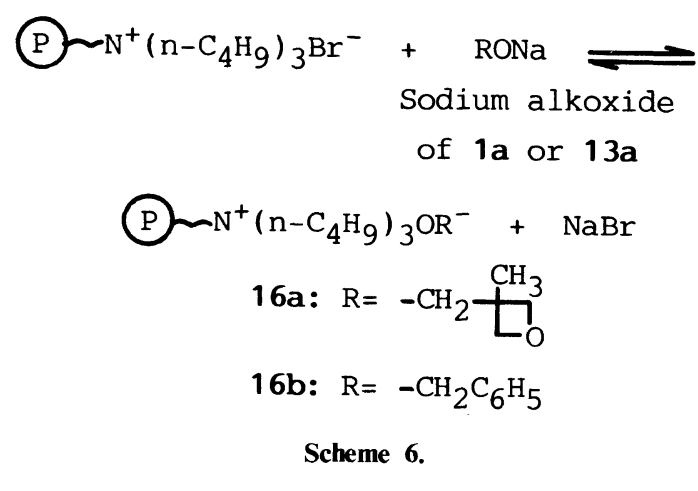

resin-based PTCs did. Concerning this problem, the following experiment was made (Figure 7). In a phase-transfer catalytic reaction between $\mathbf{1 a}$ and $\mathbf{2}$ at a molar ratio of $1: 3$ with a catalyst $\mathbf{A}-\mathbf{- 4 a N}-\mathbf{V}$, products $\mathbf{3 a}$ and 4a were formed in 76 and $1 \%$ yields, respectively, at a reaction time of $5 \mathrm{~h}$. After this time, both yields of $\mathbf{3 a}$ and $\mathbf{4 a}$ were kept around these values, suggesting a stop in the formation of $\mathbf{3 a}$ and $\mathbf{4 a}$. When the same amount of $1 \mathbf{a}$ as that initially used was added into the resultant reaction mixture to continue the reaction for an additional $17 \mathrm{~h}$, somewhat increased total amounts of products $3 \mathbf{a}$ and $\mathbf{4 a}$ were observed in the early period at the second reaction stage. After the second addition of 1a, a major part of 3a was consumed to give $\mathbf{4 a}$ and a minor part was gradually converted into by-products via a side reactions(s). The occurrence of the side reaction was confirmed by a decrease of the total amounts of $\mathbf{3 a}$ and $\mathbf{4 a}$ with an increase of the reaction time at the second reaction stage. It is known that the bromide 3a is changed to by-products such as 3-methyl-3-(2-oxa-5-hexenyl)oxetane and 1,13-bis(3-methyl-3-oxetanyl)-2,7,12-trioxatridecane. The former olefinic by-product is formed via an elimination reaction of 3a with an alkoxide counteranion of 16a which is transferred from an aqueous layer into an organic layer. ${ }^{5}$ However, the lower yields of $\mathbf{3 a}$ in phase-transfer catalyses with beads-type catalysts A-4aN-I $-\mathbf{V}$ seem not to be attributed to such side reactions, since the 
product yield of the phase-transfer catalytic reaction between $1 \mathrm{a}$ and 14 with the same catalyst was also up to $85 \%$ for 3-methyl-3-(2oxahexyl)oxetane which cannot be further changed by such side reactions because terminal bromine atoms are lacking. On the other hand, when a proper PTC, such as $\mathbf{C - 7 N}$ or $\mathbf{C}$ $8 \mathbf{N}$, was employed, more than $90 \%$ of the used 1a was consumed to produce the required products 3a and $\mathbf{4 a}$, indicating that such PTCs can transfer most of $1 \mathbf{a}$ in the form of $\mathbf{1 6 a}$ from an aqueous layer to an organic one and that the cyclic ether structures of such oxetanes as 1a, 3a, and 4a were very stable under the applied basic reaction conditions. Therefore, it is noted that, at the end of the first reaction stage with A-4aN-V, a considerable amount of 1a was left unchanged and this catalysis began to proceed again by increasing an amount of 1a at the second addition of it. In other words, in the equilibrium reaction involving the counteranion exchange on a quaternary onium cation, the rate on supplying the counteranion in the form of 16a from an aqueous into an organic layers must be enhanced by increasing the concentration of $\mathbf{1 a}$ in the aqueous layer. As discussed above, the existence of a considerably high mole fraction of hydrophobic aromatic moieties in a PTC was also undesirable for the formation of 16a from a hydrophilic alcohol $1 \mathrm{a}$ in the equilibrium reaction. On the contrary, when using more hydrophobic aralkyl alcohol 13a as a nucleophile, the formation of $\mathbf{1 6 b}$ is favored with adequate existence of hydrophobic aromatic moieties in a PTC support, resulting in almost quantitative yield of the product $15 \mathrm{a}$ by a $1.5 \mathrm{~h}$-reaction in the presence of A-4aN-V. Thus, the appreciably lower effectiveness of polyoxetane-polystyrene resinbased PTCs is thought to be due to the deficiency of softness and hydrophilicity relative to polyoxetane-based PTCs.

Furthermore, some characters of the polymeric supports used in the present study can be understood on the basis of the following findings. A somewhat hydrophilic character of polyoxetane resins was proved by the smoothness of hydrolysis of an pendant ester function attached to the resin. Hydrolysis of the acetoxyl pendant of 17a finished within 1 to $2 \mathrm{~h}$ by stirring the polymer in $2 \mathrm{moll}^{-1}$ aqueous $\mathrm{NaOH}$ and methanol under reflux. Completion of hydrolysis was confirmed on the basis of a lack of IR bands due to the ester group in the spectrum of a product $\mathbf{1 7} \mathbf{b}$. Under the same reaction conditions, somewhat prolonged reaction periods of 2 to $4 \mathrm{~h}$ were required for finishing the hydrolysis of $\mathbf{1 8 a}$ which included the hydrophobic aromatic moieties in its polyether network. However, hydrolysis of 19a hardly proceeded for $10 \mathrm{~h}$, since at this time strong IR bands due to ester group were observed. The contrasting behavior of 19a against 17a and 18a on hydrolysis may largely be a consequence of a hydrophobic, hard

Table V. Hydrolysis of pendant esters of resins $\mathrm{s}^{\mathrm{a}}$

\begin{tabular}{|c|c|c|c|c|c|}
\hline \multicolumn{4}{|c|}{ Starting polymer with a pendant ester group } & \multirow{2}{*}{\multicolumn{2}{|c|}{ Hydrolysis }} \\
\hline \multirow{2}{*}{ Name } & \multirow{2}{*}{$\begin{array}{l}\text { Functional monomer } \\
\qquad(\mathrm{A})^{\mathrm{b}}\end{array}$} & \multirow{2}{*}{$\begin{array}{l}\text { Cross linking } \\
\text { agent }(\mathrm{B})\end{array}$} & \multirow{2}{*}{$\begin{array}{l}\text { Mole ratio } \\
\text { A/B }\end{array}$} & & \\
\hline & & & & Product & $\mathrm{Time}^{\mathrm{c}} / \mathrm{h}$ \\
\hline $17 \mathbf{a}$ & Ox-OAc & $4 a$ & $70 / 30$ & $17 \mathbf{b}$ & $1-2$ \\
\hline $18 \mathbf{a}$ & Ox-OAc & $6 a$ & $74 / 26$ & $18 b$ & $2-4$ \\
\hline 19a & $\mathrm{CH}_{2}=\mathrm{C}\left(\mathrm{CH}_{3}\right) \mathrm{CO}_{2} \mathrm{CH}_{2} \mathrm{Ph}$ & $6 \mathbf{a}$ & $33 / 67$ & $19 \mathrm{~b}$ & $>10$ \\
\hline $20 \mathrm{a}$ & $\mathrm{Ox}-\mathrm{CH}\left(\mathrm{CO}_{2} \mathrm{Et}\right)_{2}$ & $4 a$ & $85 / 15$ & $20 b$ & $2-3$ \\
\hline
\end{tabular}

a Hydrolysis reaction was carried out with $2 \mathrm{moll}^{-1}$ aqueous $\mathrm{NaOH}$ in methanol under reflux.

b Ox refers to a 6-(3-methyl-3-oxetanyl)-5-oxahexyl residue.

c Reaction time of hydrolysis. 
hydrocarbon chain directly bonding a benzyloxycarbonyl group as the side chain with no spacer. In this connection, it has also been reported by us that a pendant terminal malonic ester group attached to the polyoxetane resin through a 2-oxapolymethylene spacer of 20a was smoothly converted into the corresponding dibasic acid residue of $20 \mathbf{b}$ under hydrolysis conditions similar to those applied for 19a. ${ }^{13}$ Thus, it is indicated that polyoxetane-polystyrene composite resins contain both soft, somewhat hydrophilic and hard, hydrophobic domains. Such hydrophilic character of these polyether networks may be largely due to some degree of the hydrogenbonding ability of the moderately polar ether function with water molecules.

In conclusion, $6 \mathbf{a}$ and $\mathbf{6 b}$ are considered to be important key compounds for designing a variety of functionalized polymers by twostage polymerizations using various polymerizable cyclic ethers and olefins as comonomers with functional groups in the appropriately long spacers.

\section{REFERENCES}

1. M. Kinoshita, Kaigai Kobunshi Kenkyu, 24, 201 (1980); ibid., 26, 199 (1982).

2. S. L. Regen, Angew. Chem. Int. Ed. Engl., 18, 421 (1979).

3. A. Akelah and D. C. Sherrington, Chem. Rev., 81, 557 (1981).

4. A. Akelah, Synthesis, 413 (1981).

5. M. Motoi, H. Suda, K. Shimamura, S. Nagahara, M. Takei, and S. Kanoh, Bull. Chem. Soc. Jpn., 61, 1653 (1988).

6. M. Motoi, S. Nagahara, M. Yokoyama, S. Kanoh, and H. Suda, Kobunshi Ronbunshu, 46, 59 (1989).

7. E. G. Corey and N. Raju, Tetrahedron Lett., 24, 5571 (1983).

8. D. B. Pattison, J. Am. Chem. Soc., 79, 3455 (1957).

9. J. B. Rose, J. Chem. Soc., 542 (1956).

10. L. C. Case and F. Shimoyer, U.S. Patent, 3006926 (1962) [Chem. Abstr., 56, 5934 (1962)].

11. M. Motoi, K. Shimamura, C. Shimamura, S. Muramoto, S. Kanoh, and H. Suda, Bull. Chem. Soc. Jpn., 62, 2553 (1989).

12. “Kobunshi Kagaku Jikken-ho," Kobunshi Gakkai, Ed., Tokyo-Kagaku-Dojin, Tokyo, 1981, pp 3-7.

13. M. Motoi, S. Nagahara, M. Yokoyama, E. Saito, O. Nishimura, S. Kanoh, and H. Suda, Bull. Chem. Soc. Jpn., 62, 1572 (1989). 